\title{
Efficacy and Decisional Balance to Intervene
}

\author{
Tommy Prayoga, Amanda Giovani Pea, Yosef Dedy Pradipto \\ Bina Nusantara University, Indonesia \\ ygtommyoung@gmail.com, ypradipto@binus.edu
}

\begin{abstract}
Previous studies have shown the rate of domestic violence towards women in Indonesia is increasing. Researches in the field have found that one of the most effective ways to prevent the violence was the bystander. To understand the characteristics of bystander in the sample of teenager in Indonesia, this study seeks to determine the relationship between efficacy and Decisional Balance and likelihood to intervene. The result showed that there is a significant correlation between bystander efficacy and tendency to intervene, yet no empirical support for Decisional Balance.
\end{abstract}

Keywords: Domestic violence; Bystander Intervention; Bystander Efficacy; Bystander Decisional Balance

eISSN: 2398-4279 @ 2016.: 2398-4279 @ 2016. The Authors. Published for AMER ABRA by e-International Publishing House, Ltd., UK.. This is an open access article under the CC BY-NC-ND license (http://creativecommons.org/licenses/by-nc-nd/4.0/). Peer-review under responsibility of AMER (Association of Malaysian Environment-Behaviour Researchers), ABRA (Association of Behavioural Researchers on Asians) and cEBs (Centre for Environment-Behaviour Studies), Faculty of Architecture, Planning \& Surveying, Universiti Teknologi MARA, Malaysia.

https://doi.org/10.21834/ajqol.v1i3.19 


\subsection{Introduction}

Domestic violence, being the most prominent form of Gender-based violence, has always been suppoerted by education, employment and economic discrimination (Rose, 2013). It's an issue of topical interest in today's contemporary society (Golu, 2014). It covers all type of domestic relationship, and commonly employed to describe incidents of familial or intimate abuse (Zain, 2012). The form of abuse can be sexual, physical, verbal and even psychological, mostly targeting women (Hartono, 2014). There are a few universal charactheristics of Domestic violence (Safta, Stan, lurea, \& Suditu, 2010): 1) Domestic violence is a problem that affect us all, regardless of geographical borders, age, class, race, ethnicity and cultural distinction, 2) It is the most frequent form of violence and often silenced due to the fear towards the aggressor and embarrassment and finally, 3) Domestic violence is not a private or family issue, but rather one of social interest which affects not only the victims but also the person who witness or are aware of domestic violence instances.

In Indonesia, there is an increase in the number of domestic violence cases every year, creating significant amount of physically and emotionally abused victims (Hartono, 2014). The prevalence is so high that even our closest relatives and friends might be a victim right now (Ramakrishnan, 2014). The number has been rising in heavily populated urban areas such as Greater Jakarta or Jabodetabek, especially among teenager in their family, or romantic relationships (Aisyah \& Parker, 2014. However, as there are still many unreported cases (Hayati, Hakimi, eriksson, Hogberg, \& Emmelin, 2013), it proofs that domestic violence is an iceberg phenomenon, and there are many things to be done.

Researchers have realized that the most effective approach in preventing domestic violence, is not through understanding and intervening the victim nor the abuser, but rather focusing on the bystanders that are likely to just stand by and do nothing in time of domestic violence (Banyard, 2008). Thus in recent years, the trend on the field in dealing with the problems has been swtiched to bystanders, targeting especially teenagers. Known as the 'bystander effect', it describes the phenomenon in some circumstances of violence, onlookers of the incident try to resolve the conflict in the direction of nonintervention, such as relying on the thought of a possibility that somebody, unperceived, will or had already initiated helping action (Darley \& Latane, 1968). Focusing on intervening the bystander (to take actions) in an effort to prevent domestic violence has been proven to be effective in intervention programs across nations, for example Domestic Violence Act (DVA) in Malaysia (Zain, 2012) and The Bringing in The Bystander Program (Banyard, Eckstein \& Moynihan, 2009) and yet in Indonesia there has been a little focus on this act. There were some circumstances that lead onlookers of the incident to resolve the conflict in the direction of nonintervention, such as the presence of others and the thought of a possibility that somebody, unperceived, had already initiated helping action (Darley \& Latane, 1968).

Bystanders can provide a primary prevention towards domestic violence act (Barna \& Barna, 2014) because they can provide immediate help when the incident occurs or intervene before the incident happens faster than others who are not aware or realize it yet. Through 
understanding how bystanders think and behave in facing domestic violence, researchers could increase the likelihood to engage them in intervening and preventing incidents in the future. This study will be focusing on bystander's efficacy-degree of confidence to intervene-and Decisional Balance-decisional reasoning to intervene (Banyard, 2008; Banyard, Eckstein \& Moynihan, 2009) and their relation with bystander intervention behaviors.

\subsection{Literature Review}

\subsection{Bystander Efficacy}

Efficacy is composed of a person's belief that he or she can reach an intended goal, thus Bystander Efficacy can be explained as the confidence to perform an intervening action before or during the incident of domestic violence (Banyard, Eckstein \& Moynihan, 2009). It is a degree of how much a bystander belief himself can interfere in cases of domestic violence, based on evaluation of themselves and the environment. The higher the bystander's efficacy, the more likely they will carry an actionthat will prevent or stop the course of violence action. Previous researches have shown that increase in efficacy and confidence significantly increase bystander's willingness to intervene and also related to being an active bystander (Banyard, Moynihan \& Plante, 2007) which means bystander that helps. The authors would like to see if in Indonesia, such relationship between efficacy and likelihood to help exist. Understanding how efficaacy relates in studying Bystander Intervention could potentially open up doors toward changing the attitude and behavior of bystander, especially among Indonesian teenagers.

\subsection{Decisional Balance}

Decisional Balance is the decisions reasoning that individuals must make, weighing pros ans cons before deciding to intervene (Banyard, Eckstein \& Moynihan, 2009. The concept of Decisional Balance refers to a procedure derived from Janis and Mann's (1977) decisionmaking model, assumes that some decision making involves careful scanning of all relevant considerations that enter into a "Decisional Balance" sheet of comparative potential gains and losses (cf. LaBrie, Pedersen, Thompson, \& Earleywine, 2008). Individuals that intend to help will list alternatives, efforts and the consequences of the actions, and if the downside outweigh the benefits, then they will be less likely to do it. For example, if an individual is going to stop a person larger than himself alone, the success rate will be lower than when he had companies, thus hindering the likelihood of him helping. As an often important component of many motivational interventions, the Decisional Balance penetrates a participant's state of ambivalence, clarifies competing motivational factors, and encourage the person to consider change (LaBrie, Pedersen, Thompson \& Earleywine, 2008). In this study, we seek to understand whether listing and weighing the benefits (the pros) and loss (the cons) of intervening before intervening results in active helping behavior. The details would be presented in the methods section. 


\subsection{Methodology}

\subsection{Method}

This study used the quantitative non-experimental approach, to determine the corrleational relationship between variables. The sampling method used convenience sampling to collect data from universities across Greater Jakarta.. The analysis method used was Pearson Correlation Analysis and IBM SPSS Statistics 22 program to compute the correlation analysis.

\subsection{Participants}

Participants were 93 ( 25 male and 68 female) adolescents aged 18 to 24-year-old from the urban area of Greater Jakarta or Jabodetabek ( $N=93$ ). As Siyez and Kaya (2010) suggested, adolescents are prone to violence and related situations' exposure, and as they were still establishing their value and identity, their efficacy and Decisional Balance are really important to be considered at this age, as it will potentially be rooted in them and be regarded as personal value in dealing with domestic violence onwards.

\subsection{Instruments}

Reliability index for this instruments in this study is Cronbach's Alpha $a=\geq 0.600$. The instrument used to measure Bystander Efficacy is the Bystander Efficacy Scale developed by Banyard and Moynihan (Banyard, 2008). The instrument consists of 18 items indicating behaviors that participants can express in a certain situations.

Participants were asked to rate their degree of confidence for each item describing themself through our item-Likert scale ranging from 'can't do' to 'very certain'. As explained in the introduction, we adapted the Bystander Efficacy Scale for samples in Indonesia, including translation and re-wording to Bahasa Indonesia. The result for preliminary study and reliability test are 9 items in the final version and Cronbach's alpha of $0.643(M=25.47, S D=4.06)$.

The Decisional Balance scale was also developed by Banyard and Moynihan (Banyard, 2008). The instrument consists of 11 items represents a thought that might occur to a person who is deciding whether or not to help someone who is in trouble. Participants were asked to indicate how important each items would be to them if they were considering intervensing in a situation where 'they thought someone might be being hurt or was at risk of being hurt' four item-Likert scale ranging from 'not important' to 'very important'. The Decisional Balance scale were also adapted for samples in Indonesia, including translation and re-wording to Bahasa Indonesia. The result for preliminary study and reliability test are 5 items in the final version and Cronbach's alpha of $0.743(M=13.10, S D=3.16)$.

The Bystandet Intervention Measure was developed from Koon (2013) for a study on the relationship between conformity to masculine norms and bystander interventions. It was modeled after the Bowes-Sperry and O'Leary-Kelly (2006) observer intervention typology, providing 12 items providing bystander intervention options across the domain of immediacy of intervention and level of involvement (cf. Koon, 2013). Participant were asked to rank each item 
on four item-Likert scale ranging from 'very likely' to 'very unlikely' towards performing an intervention. It includes a sample scenario for participant to base their statement rating on, and was purposefuly designed to be vague in order to reducesituational and relational variables between other witnesses and the victim (Koon, 2013). However, this study used the scale to simply measure bystander intervention only, without classifying the immediacy and level of involvement of the intervention. The scale was adapted for samples in Indonesia, including translation and wording of the items and scenario to Indonesian. No items were eliminated after pilot, and the result of preliminary study and reliability test are 12 items in the final version and Cronbach's alpha $.811(M=25.87, S D=5.04)$.

\subsection{Results and Discussions}

\subsection{Demographic results}

The demographic data obtained from the study show that there were 52 people $(55.91 \%)$ participants from Jakarta, 3 people (3.23\%) from Bogor, 13 people (13.98\%) from Tangerang, 11 people (11.83\%) from Bekasi, 4 people (4.30\%) from Depok and finally $9(9.68 \%)$ unspecified but lives in on of the five region of Jakarta. Only $9(9.68 \%)$ of them were working and $84(90.68 \%)$ others are either in college or not working currently. There were at least 86 participants who graduated from high school (79 people (84.95\%), 1 person (1.08\%) with Diploma and 6 other $(6.45 \%)$ finished college study, while the other 7 people only graduated from middle school $(7.53 \%)$. The results indicate that the participant met the requirement of the study objective and were adequate enough to represent the population and fits our criteria of participants.

\subsection{Correlation results}

The correlational results of each Independent Variables and Dependent Variable are represented in the table below.

\begin{tabular}{|c|c|c|}
\hline & Efficacy & Decisional Balance \\
\hline Pearson Correlation & $.403^{* *}$ & -.114 \\
\hline Sig (2 tailed) & .000 & .277 \\
\hline $\mathrm{N}$ & 93 & 93 \\
\hline
\end{tabular}

The table above showed that Bystander Efficacy has a positive significant correlation ( $r=$ $0.403, p 0.000<0.01$ ) with the Bystander Intervention. This means that the higher the Efficacy of a Bystander, the higher the likelihood of the Bystander Intervening. Thus, H1 was supported by empirical data. However, there were no significant correlation found between Decisional 
Balance and Bystander intervention ( $p 0.277>0.01$ ), resulting in $\mathrm{H} 2$ rejected. We will begin the disccusion for the result next.

Moving towards bystanders as intervention target was a great leap forward in combatting domestic violence. There is a need for Indonesia to also adopt this approach and apply them in effort to prevent domestic violence on many levels. Due to the little (almost none) study conducted in Indonesia, what works and what don't for Indonesian bystander was still unclear. The final result of this study, showed that bystander efficacy has a significant positive correlation with bystander intervention. It indicates that the more participants believed that they could intervene, they will be more likely to intervene during cases of domestic violence. In this sense, the study succeeded in replicating previous studies (e.g. Koon, 2013; Banyard, 2008; Banyard, Moynihan and Plante, 2007). The efficacy of bystander does really matter in determining whether bystander will intervene or not during cases of domestic violence. It shows that there is a glimpse of hope that we have the potential to benefit from bystander intervention. Efficacy is something we could be start working on in Indonesia.

On the other hand, the result of Decisional Balance were different than expected. The final value of Pearson Correlation showed no significant correlation with Bystander Intervention. It means that even if bystander weighs the benefits and the loss if they intervene, the likelihood of tendency to help afterward would still be unknown. The unsuccessful attempt to replicate the result of Decisional Balance from previous studies might be caused the scenarios may be novel and different for Indonesian, potentially resulting in unsure responds and causing errors in obtained data. The authors suggest that in deciding what to do dependes on situations and factors that each individual consider differently, thus varying the result of Decisional Balance. For example, individual from different culture might reason and consider different things from one another and it'd be difficult to determine the relationship of Decisional Balance and Bystander Intervention if we do not understand the culture. For future study, we suggest that cultural factors should be included in bystander intervetion study. Also, finding out the antescendents of Bystander Efficacy will also be important. Finally, another design of the study, for example predictive correlational or multiple regression is recommended to be used to determine the influence of bystander's beliefs and cognitive reasoning have on the tendency to prevent violence.

\subsection{Conclusion}

In an attempt to finding out the relationship between Bystander's Efficacy and Decisional Balance with the tendency to intervene during violent incidents towards women, we seek determined the correlation between both independent variables and dependent variable among 93 adolescent in Greater Jakarta. The result concluded that only Bystander Efficacy, has a significant positive relationship with the tendency to intervene in cases of domestic violence. From this result there is at least one route of great likelihood for Indonesia to develop intervention program targeting bystander based on this study that is by designing an 
intervention with an objective to increase efficacy especially among teenagers. Another result that indicates no correlation between Decisional Balance and Intervention tendency signifies a need to explore the relationship in-depth.

\section{References}

Aisyah, S. \& Parker, L. (2014). Problematic conjugations: Women's agency, marriage and domestic violence in Indonesia. Asian Studies Review, 38(2), 205-223.

Banyard, V. L. (2008). Measurement and correlates of prosocial bystander behavior: The case of interpersonal violence. Violence and Victims, 23(1), 83-97.

Banyard, V. L., Eckstein, R. P. \& Moynihan, M. M. (2010). Sexual Violence Prevention The Role of Stages of Change. Journal of Interpersonal Violence, 25(1), 111-135.

Banyard, V. L., Moynihan, M. M. \& Plante, E. G. (2007). Sexual violence prevention through bystander education: An experimental evaluation. Journal of Community Psychology, 35(4), 463-481.

Barna, I. \& Barna, O. (2014). The Effectiveness of School-based Violence Prevention Programs for Reducing Aggressive Behaviour. Procedia-Social and Behavioral Sciences, 137, 88-92.

Darley, J. M. \& Latane, B. (1968). Bystander intervention in emergencies: diffusion of responsibility. Journal of personality and social psychology, 8(4p1), 377.

Golu, F. (2014). Predictors of Domestic Violence-Comparative Analysis.Procedia-Social and Behavioral Sciences, 127, 611-615.

Hayati, E. N., Eriksson, M., Hakimi, M., Högberg, U. \& Emmelin, M. (2013). 'Elastic band strategy': women's lived experiences of coping with domestic violence in rural Indonesia. Global Health Action, 6

Hartono, B. (2014). Bentuk Perlindungan Hukum Terhadap Perempuan Pelapor Selaku Saksi Korban Kekerasan Dalam Rumah Tangga. KEADILAN PROGRESIF, 5(1).

Koon, J. A. (2013). Masculinity and bystander helping behavior: a study of the relationship between conformity to masculine norms and bystander interventions.

LaBrie, J. W., Pedersen, E. R., Thompson, A. D. \& Earleywine, M. (2008). A brief Decisional Balance intervention increases motivation and behavior regarding condom use in high-risk heterosexual college men. Archives of sexual behavior, 37(2), 330-339.

Ramakrishnan, M. S. (2014). Speak Out: Teaching Domestic Violence in Your Literature Classroom. Procedia-Social and Behavioral Sciences, 118, 296-301.

Rose, S. D. (2013). Challenging global gender violence. Procedia-Social and Behavioral Sciences, 82, 61-65.

Safta, C. G., Stan, E., lurea, C. \& Suditu, M. (2010). Counseling and Assistance for Women Victims of Domestic Violence in Romania-Case Study.Procedia-Social and Behavioral Sciences, 5, 2034-2041. 
Prayoga, T., et.al. / Asian Journal of Quality of Life, AjQoL,1(3), September/October 2016 (p.11-19)

Siyez, D. M. \& Kaya, A. (2010). The influence of some psychological problems and socio-demographic variables upon attitudes toward violence in adolescence. Procedia-Social and Behavioral Sciences, 5, 334-338. 